\title{
Mariana Nelly, The 'Fairfax Sequence' Reconsidered: Charles d'Orléans, William de la Pole, and the Anonymous Poems of Bodleian MS Fairfax 16
}

\section{Paola Cifarelli}

\section{(2) OpenEdition Journals}

Édition électronique

URL : https://journals.openedition.org/studifrancesi/3025

DOI : 10.4000/studifrancesi.3025

ISSN : 2427-5856

Éditeur

Rosenberg \& Sellier

Édition imprimée

Date de publication : 1 juillet 2013

Pagination : 436

ISSN : 0039-2944

\section{Référence électronique}

Paola Cifarelli, « Mariana Nelly, The 'Fairfax Sequence' Reconsidered: Charles d'Orléans, William de la Pole, and the Anonymous Poems of Bodleian MS Fairfax 16 ", Studi Francesi [En ligne], 170 (LVII | II) | 2013, mis en ligne le 30 novembre 2015, consulté le 02 février 2023. URL : http://journals.openedition.org/ studifrancesi/3025; DOI : https://doi.org/10.4000/studifrancesi.3025

Ce document a été généré automatiquement le 2 février 2023.

\section{c)}

Creative Commons - Attribution - Pas d'Utilisation Commerciale - Pas de Modification 4.0 International - CC BY-NC-ND 4.0

https://creativecommons.org/licenses/by-nc-nd/4.0/ 


\title{
Mariana Nelly, The 'Fairfax Sequence' Reconsidered: Charles d'Orléans, William de la Pole, and the Anonymous Poems of Bodleian MS Fairfax 16
}

\author{
Paola Cifarelli
}

\section{RÉFÉRENCE}

MARIANA NELLY, The 'Fairfax Sequence' Reconsidered: Charles d'Orléans, William de la Pole, and the Anonymous Poems of Bodleian MS Fairfax 16, «Fifteenth Century Studies», 36, 2011, pp. 127-136.

Bien que le manuscrit Fairfax 16 contienne des poèmes en moyen anglais, cette étude est intéressante pour les spécialistes de la littérature française dans la mesure où ceuxci permettent de mesurer l'influence que la personnalité de Charles d'Orléans exerça sur le milieu poétique d'Outre Manche, surtout pour ce qui est de la conception du recueil lyrique indépendant comme jeu social. La séquence en question, qui date de 1450 environ, est examinée dans la perspective de la paternité des vers anonymes, que l'A. attribue à William de la Pole, duc de Suffolk, dont les contacts avec les illustres prisonniers français sont bien connus. 